\title{
CIRCUITOS ESPACIAIS DA PRODUÇÃO, CÍRCULOS DE COOPERAÇÃO E A MODERNIZAÇÃO DO SETOR AGRÍCOLA BRASILEIRO
}

\author{
SPATIAL CIRCUITS OF PRODUCTION, COOPERATION CIRCLES AND THE MODERNIZATION OF \\ THE AGRICULTURAL SECTOR IN BRAZIL
}

Luis Angelo dos Santos Aracri ${ }^{\mathrm{A}}$

${ }^{\text {A }}$ Universidade Federal Juiz de Fora (UFJF), Juiz de Fora, MG, Brasil

Recebido em: $12 / 11 / 2021$ | 04/01/2022

DOI: $10.12957 /$ tamoios.2022.63437

Correspondência para: Luis Angelo dos Santos Aracri (luis.aracri@ufjf.edu.br)

\begin{abstract}
Resumo
O presente artigo foi desenvolvido a partir de uma palestra proferida pelo autor em junho de 2021 em um curso sobre a geografia do agronegócio no Brasil, ministrado no Programa de Pós-Graduação em Geografia da Universidade Federal do Rio de Janeiro. Tem como objetivo propor uma reflexão sobre a modernização do setor agrícola brasileiro com base nas contribuições de Milton Santos, com destaque para o par conceitual circuitos espaciais da produção / círculos de cooperação. No presente texto, é dada uma ênfase maior aos círculos de cooperação, tendo em vista que estes têm sido menos estudados pelos geoógrafos. Face à questão da modernização do setor agrícola, este paper se atém, principalmente, às formas de cooperação entre firmas e instituições ligadas ao agronegócio e universidades e centros de pesquisa.
\end{abstract}

Palavras-chave: circuitos espaciais da produção; círculos de cooperação; modernização do setor agrícola.

\begin{abstract}
This article was developed from a lecture given by the author in June 2021 in a course on the geography of agribusiness in Brazil at the Program of Postgraduate Studies in Geography, Federal University of Rio de Janeiro. Its objective is to propose a reflection on the modernization of the Brazilian agricultural sector based on the contributions of Milton Santos, with an emphasis on the following conceptual pair: spatial circuits of production / cooperation circles. In this text, greater emphasis is given to the cooperation circles, considering that these ones have been less studied by geographers. Faced with the issue of modernization of the agricultural sector, this paper focuses mainly on forms of cooperation between firms and institutions linked to agribusiness and universities and research centers.
\end{abstract}

Keywords: spatial circuits of production; cooperation circles; modernization of the agricultural sector. 


\section{INTRODUÇÃO}

$\mathrm{Na}$ história recente da geografia agrária brasileira temos visto um número cada vez maior de trabalhos acadêmicos que vêm se dedicando ao estudo das relações entre a expansão do setor de agronegócios no país e as transformações na dinâmica e no funcionamento do território, com base em um par conceitual proposto e desenvolvido por Milton Santos, com o intuito de compreender como diferentes parcelas do espaço geográfico se articulam entre si segundo uma lógica global. Esse par conceitual é formado pelas noções de circuito espacial da produção - que alguns autores chamam simplesmente de circuitos produtivos - e de círculos de cooperação (SANTOS, 1988; SANTOS e SILVEIRA, 2002). São conceitos que orientam nossa atenção e nosso olhar para as interações espaciais e sua multiescalaridade e, principalmente, para o fenômeno da circulação.

E essa talvez seja a principal razão pela qual alguns estudiosos do agronegócio, que pertencem ao campo da geografia, vêm tentando trabalhar com esse par conceitual: dado o caráter global das cadeias produtivas agroindustriais, o processo produtivo, na sua totalidade, é multiescalar. Quando dizemos que o processo produtivo se dá em múltiplas escalas, significa que cada etapa ou cada parcela desse processo estabelece interações com o espaço que vão desde a escala regional (quando, por exemplo, estamos falando das relações entre cidade e campo), até a escala internacional (comércio exterior, exportações). Essas interações espaciais multiescalares são efetivadas pela circulação, que é o que possibilita os fluxos e os intercâmbios entre os lugares, sejam eles próximos ou distantes.

Mas, de acordo com Santos (1988), essas interações ou esses fluxos não são de natureza exclusivamente material - não estamos falando apenas da circulação de matérias-primas, de insumos, de máquinas e implementos agrícolas ou de produtos finais. Segundo o autor, esses fluxos de ordem material são perpassados pelo trânsito de elementos que podemos chamar de "intangíveis", ou seja, por fluxos de natureza imaterial: ações, ordens, decisões, informacões, ideias, conhecimento (tácito ou codificado) etc. Neste caso, em particular, o princípio da multiescalaridade também se aplica: não apenas porque as interações espaciais definidas por esses fluxos imateriais diferem com relação à sua extensão no espaço, mas também porque toda coordenação e gestão do processo produtivo, tanto em cada uma de suas partes, quanto em seu conjunto, envolve diferentes níves e escalas de decisão. Se, por um lado, os circuitos espaciais da produção se referem às interações e aos vínculos espaciais definidos pelos fluxos de ordem material, por outro, os círculos de cooperação, que se associam aos circuitos, são definidos pelos fluxos imateriais.

Todavia, ainda se verifica um notável desequilíbrio nos trabalhos aos quais nos referimos: escreve-se muito sobre os circuitos produtivos nos mais distintos setores de agronegócios, mas muito pouco se produz ou se avança sobre seus respectivos círculos de cooperação (ARACRI, 2021). No entanto, defendemos que uma maneira possível de se empreender uma análise conjunta, isto é, sem o exame dos circuitos produtivos e dos círculos de cooperação no agronegócio como entidades dissociadas, é através do estudo da modernização do setor agrícola - que é o que procuraremos demonstrar ao longo do presente artigo. Essa tarefa, de antemão, nos impõe o enfrentamento de duas questões fundamentais: (1) explicar o que se entende aqui por "setor agrícola"; e (2) esclarecer, em seguida, o que seria a "modernização" desse setor.

O setor agrícola aqui é compreendido, nos termos propostos por Bernstein (2011): é o setor representado pela produção agropecuária e as atividades e instituições especializadas situadas à sua montante e à sua jusante. Por sua vez, a modernização do setor agrícola seria o conjunto das mudanças tecnológicas (ou seja, mudanças nas técnicas e nos processos de produção e distribuição de produtos e serviços) e das mudanças organizacionais que lhes são 
subjacentes (descentralização de atividades, especialização dos agentes). Além disso, estamos falando de uma modernização caracterizada por um input científico cada vez maior.

A hipótese aqui defendida é a de que a modernização não somente está na gênese dos circuitos espaciais e dos círculos de cooperação no agronegócio, como também ela própria é um produto desses circuitos espaciais e dos círculos que a eles se associam. Nosso objetivo no presente trabalho é apresentar uma reflexão sobre essa relação. Entretanto, uma ênfase especial será dada ao papel dos círculos de cooperação que, no nosso entendimento, vem sendo pouco aprofunado de uma maneira geral.

\section{UMA BREVE HISTÓRIA DA NOÇÃO DE CIRCUITO: DE QUESNAY A SANTOS}

A ideia de circuito como forma de pensar a vida econômica sob a perspectiva das interações espaciais mediadas pela circulação de mercadorias não surge originalmente na geografia. O primeiro a fazer essa leitura foi o economista fisiocrata François Quesnay, em meados do século XVIII, quando ele se dedicou ao estudo do consumo, nas cidades, da riqueza produzida nas zonas rurais (CLAVAL, 2005). Já no século XIX, a teoria do ciclo do capital (D - M - D') de Karl Marx era uma tentativa de explicar a relação entre produção e circulação de mercadorias, no âmbito da qual a troca do dinheiro por força de trabalho, matérias-primas e meios de produção, que eram encaminhados para as unidades de produção, e a subsequente circulação do produto final, ocorriam no "mercado" - que nesse caso, se formalizava na cidade (é preciso esclarecer que, no entanto, Marx estava, nesse caso, se referindo à indústria urbana). Os geógrafos que mais tarde tentaram importar ou adaptar esse modelo para os estudos em geografia econômica e geografia urbana se utilizaram desse esquema para explicar os relacionamentos espaciais e o processo de reprodução dos espaços urbano-industriais (CARLOS, 1988).

A noção de circuito também permeia, ainda que de maneira implícita, os modelos e teorias da economia espacial que se tornaram clássicos, como a "Teoria do Estado Isolado" de Johann Von Thünen, a "Teoria da Localização Industrial" de Alfred Weber, ou a "Teoria dos Lugares Centrais" de Walter Christaller. Ao tentar compreender a lógica por trás da localização e da distribuição espacial das atividades agrícolas, industriais e comerciais (terciárias), esses autores enfatizaram a relação entre localização e interações espaciais (intercâmbios com mercados fornecedores, com mercados consumidores etc) e o papel da distância e dos custos de transportes (ou seja, da circulação) entre esses espaços sobre os lucros e os ganhos (CLAVAL, 2012). Mais tarde, esses modelos, principalmente o dos lugares centrais de Christaller, constituíram a base da chamada "ciência regional" nos anos 1950.

$\mathrm{Na}$ década de 1970, Milton Santos vai reelaborar a noção de circuito na geografia a partir da crítica ao modo como a academia e os órgãos ligados ao planejamento haviam se apropriado das teorias da economia espacial para explicar a urbanização nos países subdesenvolvidos. É a partir dessa crítica que surge a teoria dos dois circuitos da economia urbana (SANTOS, 2004), que servirá de base para uma reelaboração posterior, que é a teoria dos circuitos espaciais da produção (SANTOS, 1988). Segundo o autor, o espaço nos países subdesenvolvidos se reveste de características distintas do espaço nas economias mais avançadas. Essas características seriam: (a) significativa desigualdade na distribuição da renda, fenômeno que se reflete não apenas no nível dos indivíduos e das classes sociais, mas também no nível intraurbano e regional; e (b) maior e mais profunda hierarquização das atividades econômicas, sendo que, na escala local, existem atividades de mesma natureza, mas de níveis diferentes. Em outras palavras, as possibilidades de consumo variam muito entre os indivíduos e as classes sociais, o que contribuiu para uma maior hierarquização entre 
produtores e consumidores de bens e serviços e entre as diferentes parcelas do espaço geográfico.

Sendo assim, a economia urbana e o espaço geográfico nos países subdesenvolvidos seriam estruturados com base em dois circuitos econômicos: o superior e o inferior. O circuito inferior é formado por atividades de pequena dimensão, com foco no consumo da população mais pobre. É o circuito da economia popular. Como o objeto deste trabalho é o agronegócio, o circuito inferior não receberá aqui nossa atenção. Para falar de agronegócio e modernização do setor agrícola, nos interessa mais abordar o circuito superior. Isso porque, para Milton Santos, a gênese desse circuito está diretamente associada à modernização tecnológica, tanto na esfera da produção quanto da circulação (SANTOS, 2004). Isso porque ele é constituído, em grande parte, por atividades intensivas em capital e se desenvolve sobre uma moderna infraestrutura de transportes e comunicações que começou a se difundir na escala planetária a partir da década de 1970 - sendo que essa infraestrutura começou a penetrar com mais força (e de maneira mais desigual e seletiva) nos territórios dos países da periferia do capitalismo quase duas décadas depois.

O circuito superior seria, portanto, constituído por comércio e indústria de exportação, serviços de apoio modernos, transportadoras, além de bancos e instituições financeiras. São atividades que operam com produção em larga escala para atender a demanda de mercados grandes e espacialmente distantes. $\mathrm{O}$ circuito superior conta ainda com a presença de grandes firmas, incluindo as de capital estrangeiro, que investem pesadamente em publicidade e marketing como forma de induzir mudanças nos padrões de consumo. Esse dado é particularmente importante para o estudo da relação entre circuitos econômicos e agronegócio, porque as mudanças nos padrões alimentares, sobretudo das classes média e alta urbanas, são um dado essencial para entender o sistema agroalimentar global. Essencialmente, as relações que estruturam esse circuito não se limitam à escala da cidade ou da região e extrapolam para as escalas nacional e internacional. E isso ocorre porque historicamente os espaços dos países subdesenvolvidos se organizam (ou se reogranizam) em função de interesses distantes, principalmente na escala internacional.

Ao longo da década de 1980, à medida que o então novo ciclo de expansão do capitalismo, que passou a ser chamado de "globalização", deixou de ser apenas o que o Santos (1988) chamou de um "processo longamente preparado" para se tornar algo real e concreto, ele atualizou a noção de circuito superior da economia através do conceito de circuito espacial produtivo. Mas o que motivou essa atualização conceitual? Para o autor, a globalização havia tornado ultrapassadas as definições tradicionais de região, e também de outros termos associados à análise regional, como rede urbana ou relação cidade-campo. Não quer dizer que região, rede urbana e relação cidade-campo deixaram de existir. Mas o conteúdo e a forma desses aspectos da realidade concreta foram modificados.

As regiões teriam se tornado "suporte das relações globais" (SANTOS, 2002), transformando-se, assim, em parcelas ou subespaços articulados entre si na escala global, e que passaram a apresentar uma tendência cada vez maior de se especializarem economicamente. De acordo com o autor, as regiões não precisam mais produzir tudo o que necessitam para subsistir: as modernizações tecnológicas, tanto na esfera da produção quanto na esfera da circulação, e as mudanças organizacionais, criaram condições novas de acessibilidade espacial e ampliaram a capacidade das grandes firmas de poder tirar proveito das diferenças espaciais, tanto dentro dos territórios nacionais quanto em territórios estrangeiros. O circuito espacial seria, então, as diversas etapas pelas quais passaria um produto, desde a aquisição das matérias-primas até o consumo final da mercadoria acabada (SANTOS, 1988). Naturalmente, quando nos deparamos com essa definição, logo nos vem à 
mente a seguinte pergunta: o circuito espacial de produção não seria a noção cadeia produtiva global com um outro rótulo, com outra etiqueta?

Conforme dissemos em outra ocasião (ARACRI, 2021), a resposta é não. Cadeias produtivas globais e circuitos espaciais de produção são coisas distintas, já o demonstraram Castillo e Frederico (2011). Porém, não são noções totalmente descoladas entre si. A principal diferença entre elas é o foco da análise. No caso das cadeias produtivas globais, o centro da análise são os vínculos inter-setoriais (os elos entre os segmentos da cadeia) e o objetivo é designar o conjunto de atividades que representam genericamente um setor de atividades (ex.: setor sucroenergético/sucroalcooleiro; indústria de laticínios). Em se tratando de circuitos espaciais de produção, o foco são as interações espaciais e o objetivo é a análise do processo de compartimentação, segmentação, integração e gestão do território sob a égide de um determinado setor. Como podemos constatar, são conceitos que tratam, sim, de coisas distintas, mas que são, ao mesmo tempo, indissociáveis: os vínculos inter-setoriais se dão através de fluxos entre os segmentos das cadeias (realizados através do processo de circulação) e, dessa forma, geram relacionamentos espaciais (ARACRI, 2021).

\section{CIRCUITOS PRODUTIVOS, CÍRCULOS DE COOPERAÇÃO E MODERNIZAÇÃO DO SETOR AGRÍCOLA}

No âmbito do presente trabalho, consideramos que o par conceitual circuito espacial de produção / círculo de cooperação dialoga de maneira mais eficiente com o conceito de setor agrícola de Bernstein (2011) do que, por exemplo, a noção de cadeia produtiva global. O conceito de setor agrícola, como o dissemos alhures, não engloba apenas as atividades e os segmentos especializados à montante e à jusante da produção agropecuária, ou seja, não engloba apenas os vínculos entre esses segmentos, que se dão através de fluxos exclusivamente de ordem material; ele abrange, também, instituições, como por exemplo sindicatos rurais patronais, associações de empresas de um determinado ramo da agroindústria, organizações de interesse privado de apoio a determinados setores de agronegócios, além de universidades e centros de pesquisa, empresas de extensão rural etc. Ou seja, é um conceito que permite contemplar, também, os vínculos constituídos com base nos "fluxos imateriais".

É no tocante a esse ponto que entra em cena o papel dos círculos de cooperação, sem os quais falar de circuitos espaciais não faria sentido. Os círculos de cooperação são os vínculos mediados pelos fluxos de ordem imaterial mantidos entre os segmentos e as instituições de um setor. Por envolver um conjunto de ações, decisões, ordens, informações, ideias, conhecimentos, etc, os círculos de cooperação são o que o Santos e Silveira (2001) denominaram de "inteligência do capital". Mas a questão que se impõe a partir de agora é: como podemos interpretar o processo de modernização do setor agrícola no Brasil, em termos geográficos/espaciais, tendo como ferramentas analíticas as noções de círculos de cooperação e de circuitos produtivos?

Dois vetores fundamentais para a compreensão da modernização da produção agropecuária no Brasil e, consequentemente, de sua integração com diferentes ramos da indústria, são o crédito rural e a pesquisa e assistência técnica rurais (GONÇALVES NETO, 1997). Como vetores indutores da modernização do campo, o crédito, a pesquisa e a assistência técnica contribuíram com o acréscimo progressivo de objetos industriais nos espaços agrários. Isso possibilitou, de um lado, a integração da produção agropecuária com a chamada "indústria para a agricultura" (SILVA, 1998) mediante esse emprego crescente de máquinas e implementos, de fertilizantes, de defensivos químicos etc. De outro, permitiu, 
também, tanto o cultivo de maiores extensões de terra sem um crescimento correspondente de força de trabalho, quanto o aumento da produtividade em uma mesma unidade de área (SANTOS e SILVEIRA, 2001). O resultado foi o incremento da escala de produção e a produção de excedentes apropriados pela agroindústria processadora e por empresas comerciais que atuam no encaminhamento das commodities para o mercado externo - as tradings.

Cabe ressaltar que a entrada de firmas comerciais e industriais estrangeiras no setor agrícola nacional implicou na importação de técnicas e processos de produção diretamente de suas matrizes no exterior - um fenômeno que ficou conhecido na literatura econômica como "atalho tecnológico" (BAUMGARTEN, 2011). E à medida em que a nova divisão do trabalho resultante desse processo se amplia e se aprofunda, vão sendo agregados ao circuito diversas atividades e serviços de suporte e cresce concomitantemente a tendência à especialização dos agentes. Alguns exemplos são os serviços de transportes e logística, as empresas de consultoria agropecuária, as revendedoras de pacotes tecnológicos, etc. Aí podemos então observar as mudanças organizacionais, que são representadas por esse processo crescente de especialização dos agentes e de descentralização de atividades, e que são indissociáveis das mudanças de ordem técnica. Cabe ressaltar que as modernizações associadas aos circuitos espaciais da produção no setor agrícola também se materializam através da modernização e/ou criação de capitais fixos: infraestruturas de transportes e de comunicações, instalações de armazenagem, unidades agroindustriais, frigoríficos, aviários, condomínios logísticos, etc.

Como resultado, a modernização das atividades que compõem os circuitos agroindustriais de produção não apenas incrementa a densidade técnica das parcelas do território onde se encontram instaladas ou abrigadas, mas também aprofunda a densidade normativa ${ }^{1}$ desses espaços, porque enquadram a produção em determinados parâmetros de custos, eficiência, produtividade e qualidade. Os objetos técnicos introduzidos, tal como "Cavalos de Troia" (SANTOS, 2002), trazem consigo novas ações, novos savoir faire, ou mesmo novas racionalidades, muitas vezes de origem distante e alheias aos lugares. Essas novas racionalidades determinam o que vai ser produzido, como (de que maneira) e quanto (ARACRI, 2012).

Mas e os círculos de cooperação? Onde eles se encaixam em todo esse esquema? Primeiramente, nunca é demais repetir que, ao contrário dos circuitos espaciais, os círculos de cooperação vem sendo muito pouco estudados. Uma possível explicação para esse problema é o fato de que os círculos de cooperação adquirem concretude sob formas muito variadas. Um mesmo circuito espacial pode ser perpassado por diferentes formas ou redes de cooperação e com diferentes finalidades e propósitos. Se nos atermos, por exemplo, às formas de cooperação das quais participam exclusivamente as firmas, podemos destacar aqui algumas estratégias no campo organizacional, como as alianças estratégicas e as joint ventures.

Citemos aqui dois casos. No setor sucroenergético, podemos destacar aqui a criação, em 2010, da Raízen, que é uma joint venture formada entre a companhia brasileira Cosan S.A. e a Shell. Nesse caso temos uma parceria inter-empresarial cuja administração passa pela criação de uma terceira empresa. No caso das alianças estratégicas, não existe essa figura da terceira empresa que tem o papel de assumir a gestão da parceria. Para contrapor o exemplo da Raízen, temos então o caso do COPASUL (Cooperativa Agrícola Sul Mato-Grossense) no circuito espacial do algodão, que firmou um acordo de cooperação com a Valley, empresa norteamericana do ramo de sistemas de irrigação. Nessa parceria, a COPASUL tem exclusividade na comercialização dos sistemas de irrigação e das peças de reposição da Valley para o seus cooperados, além da prestação da assistência técnica, com ganhos através de comissões. Esse segundo exemplo tem, como o leitor pode observar, especial significância 
para nossas reflexões sobre a modernização do setor agrícola, nesse caso o setor algodoeiro em Mato Grosso do Sul.

Todavia, tendo em vista que o setor agrícola, como já dissemos anteriormente, não é constituído apenas por firmas, mas também por instituições, podemos inferir que os círculos de cooperação podem compreender uma diversidade de atores: empresas, associações, entidades representantes da sociedade civil, órgãos e instituições públicos etc. Em se tratando de agronegócio, vem ganhando terreno nos últimos anos as formas de cooperação denominadas de "governança territorial", que são iniciativas de desenvolvimento territorial ou regional através de ações resultantes do envolvimento conjunto e cooperativo de diversos atores sociais, principalmente aqueles ligados ao tripé Estado-empresas-sociedade civil (DALLABRIDA, 2011). Esse é o caso, por exemplo, dos chamados "arranjos produtivos locais" (APLs), terminologia usada aqui no Brasil para designar os aglomerados de empresas especializadas de um determinado ramo da indústria ou setor de atividades em uma mesma parcela do território que mantém diversas formas de interação e cooperação entre si e com outros atores, como o poder público, associações, sindicatos, universidades e centros de pesquisa, etc. (VALE e CASTRO, 2005).

Os APLs emergem exatamente nesse contexto, no âmbito do qual, a especialização produtiva regional e a constituição de circuitos espaciais podem ser consideradas duas faces de um mesmo fenômeno. Um exemplo no estado Minas Gerais é a criação do "APL dos Biocombustíveis", que foi legalmente instituído através de uma resolução formulada de maneira conjunta por três secretarias de estado: Ciência, Tecnologia e Ensino Superior; Desenvolvimento Econômico; Agricultura, Pecuária e Abastecimento (FRANCO e FONSECA, 2010). O APL dos Biocombustíveis abrange três polos regionais: o sucroenergético no Triângulo Mineiro, o de biodiesel e óleos vegetais no Norte de Minas e o de carvão vegetal e biomassa na Região Central Mineira. Há uma descentralização de competências e o Comitê Gestor do APL é formado pelas secretarias anteriormente mencionadas, pelos sindicatos das indústrias de bioenergia dos três polos e, também, por universidades.

É importante que se registre aqui que o número de trabalhos no campo da geografia dedicados ao estudo das formas de governança territorial vem aumentando bastante nos últimos anos, mas essas pesquisas, entretanto, estão mais atreladas ao debate institucionalista ou aos novos estudos sobre desenvolvimento regional e territorial do que à linha de pesquisa sobre circuitos espaciais de produção, infelizmente. Contudo, conforme fora proposto na introdução deste trabalho, a questão de maior interesse aqui é a modernização do setor agrícola. Logo, deste ponto em diante daremos maior ênfase às formas de cooperação que vêm contribuindo com o incremento do input científico das atividades que integram os circuitos produtivos ligados ao agronegócio: as interações entre os agentes do setor produtivo agrícola e as universidades e centros de pesquisa, também denominadas de instituições científico-tecnológicas (ICTs).

Deve-se destacar que no Brasil o relacionamento entre universidades e empresas foi regulamentado pela Lei n. 10.973, de 2004, que é conhecida como "Lei de Inovação". E na sequência dela, foram criadas outras "leis de inovação" semelhantes em todos os estados da federação. Além disso, existem atualmente duas grandes bases de dados para estudos sobre cooperação entre setor produtivo e universidades e centros de pesquisas no Brasil, que são a Pesquisa Nacional de Inovação Tecnológica (PINTEC), do Instituto Brasileiro de Geografia e Estatística (IBGE), e o Censo do Diretório dos Grupos de Pesquisa do Conselho Nacional de Pesquisa Científica e Tecnológica (CNPq). O problema, no entanto, é que essas bases de dados já estão bastante desatualizadas. A última PINTEC foi realizada em 2017; e, no caso do Censo dos Diretórios dos Grupos de Pesquisa do CNPq, os levantamentos realizados após 
2010 só tiveram as súmulas estatísticas divulgadas, não sendo possível, portanto, ter acesso aos dados mais recentes sobre quantas e quais empresas declararam ter relacionamentos com grupos de pesquisa sediados no país e vice-versa.

Segundo a PINTEC de 2017, a indústria de produtos alimentícios é o segmento que verificou o maior índice de implementação de inovações de produto, de processo, de marketing e organizacionais no país: isso corresponde a $14 \%$ do total das indústrias de transformação que declararam ter implementado inovações (atrás dela temos a indústria de confecção de artigos de vestuário e acessórios e de fabricação de produtos de metal, com 13 e $9,6 \%$, respectivamente). Ainda de acordo com a pesquisa, cerca de $88 \%$ das inovações de produto foram desenvolvidas pelas próprias empresas, mas quando a variável examinada passa a ser inovações de processo, esse índice cai para $21,7 \%$. Das inovações de processo implementadas que não são de desenvolvimento próprio, $71,5 \%$ foram desenvolvidas por outras outras empresas ou por instituições de pesquisa, sendo que apenas 5\% resultaram de parcerias e redes de cooperação entre as empresas declarantes, outras empresas e instituições científico-tecnológicas.

Mas isso pode variar de acordo com a parcela do território que se observa. A mesma pesquisa mostra, por exemplo, que em Mato Grosso, $86 \%$ das firmas do setor de produtos alimentícios implantaram inovações desenvolvidas em cooperação com outras empresas ou com universidades e centros de pesquisa. $\mathrm{O}$ exame do segmento agropecuário também revela dados bastante elucidativos. De acordo com o Censo 2010 do Diretório dos Grupos de Pesquisa do CNPq, no Brasil 20,16\% dos grupos de pesquisa sediados no país que declararam ter relacionamentos com o setor produtivo são da grande área de "ciências agrárias"; esse número indica de que se trata da grande área do conhecimento com o maior número de relacionamentos na escala nacional. Mas tomemos agora o exemplo de dois estados brasileiros que fazem parte, há alguns anos, da nossa própria trajetória de pesquisa: Mato Grosso e Minas Gerais. Em MT, 26\% dos grupos de pesquisa do CNPq que declararam ter relacionamentos com o setor produtivo são da grande área de ciências agrárias; e, nesse caso, também é a grande área do conhecimento com o maior número de relacionamentos no estado. E o mesmo ocorreu em MG em 2010: 31,5\% dos grupos de pesquisa que confirmaram ter parcerias com empresas eram, também, do campo das ciências agrárias.

Os dados não apenas mostram que o agronegócio no Brasil parece se servir bem da infraestrutura nacional de ciência e tecnologia, mas também que Mato Grosso e Minas Gerais, estados que abrigam setores de agronegócios importantes para a economia nacional (soja, carnes, leite e derivados, biocombustíveis) estavam, em 2010, acima da média nacional no tocante à cooperação entre empresas e instituições de pesquisa para o desenvolvimento de inovações para os segmentos vinculados ao setor agrícola.

\section{CÍRCULOS DE COOPERAÇÃO PARA O DESENVOLVIMENTO DE INOVAÇÕES AGRÍCOLAS: AS EXPLICAÇÕES DA GEOGRAFIA}

De acordo com Campi (2011), do mesmo modo que é possível identificar particularidades internas inerentes aos diferentes setores de atividades, o mesmo ocorre com o desenvolvimento de novas tecnologias, que apresentam especificidades segundo o contexto em que têm lugar. Em outras palavras, as tecnologias incorporadas em produtos e processos de produção no setor agrícola na periferia do capitalismo foi gerada nos países desenvolvidos, o que significa dizer que foram pensadas para outras realidades. Isso também significa dizer que a transferência dessa tecnologia para países como o Brasil, não poderia ser feita de 
maneira plena sem adaptação dessas técnicas às condições nacionais, regionais ou até mesmo locais de produção.

A percepção de que a tecnologia empregada não era diretamente transferível ocorreu quando o Governo brasileiro se deu conta dos limites e problemas da política de modernização do campo com base na extensão rural na década de 1960 (GONÇALVES NETO, 1997). Foi essa demanda que deu origem ao processo de organização da pesquisa agropecuária no país. Só que a criação de um "setor" gerador de inovação no Brasil se adequou às pautas das políticas agrícola e econômica nacionais. Isto quer dizer que a pesquisa agropecuária brasileira, bem como as diversas políticas de incentivo ao setor agrícola, vêm privilegiando desde então determinadas culturas, principalmente as exportáveis. A soja, por exemplo, é uma dessas culturas.

A Rede de Pesquisa CESB, que já foi objeto de nossa atenção em um outro trabalho (ARACRI, 2021), é um caso bastante ilustrativo. Trata-se de uma rede de cooperação da qual fazem parte o Comitê Estratégico Soja Brasil (CESB), uma organização da sociedade civil de interesse público (OSCIP), fundada no final da década de 1990, com o objetivo de integrar e difundir conhecimentos em favor da cultura da soja no país, a EMBRAPA Cerrados (com sede em Brasília) e a EMBRAPA Soja (com sede em Londrina, no Paraná), e produtores de soja de todas as partes do país, individuais ou organizados em cooperativas. Uma das linhas de atuação da rede é o acompanhamento de práticas utilizadas por produtores de soja, com foco no aumento da produtividade. As atividades são monitoradas e avaliadas pela CESB, em parceria com a EMBRAPA Cerrados e a EMBRAPA Soja, e as práticas que se comprovam mais eficientes passam a ser recomendadas e difundidas por essas instituições através da assistência técnica.

A outra linha de ação da Rede de Pesquisa CESB é a elaboração dos "protocolos de pesquisa", instrumentos através dos quais são propostos problemas e questões para a pesquisa científica. Dessa forma, pretende-se atrair universidades e centros de pesquisa interessados em desenvolver projetos com foco nessas demandas. Uma das questões mais pautadas pelos protocolos de pesquisa é o problema da nutrição dos solos, principalmente parâmetros de dosagem e métodos de aplicação. Para a produção de soja em Mato Grosso, para ficarmos em um exemplo concreto, esse é um ponto particularmente importante. Uma das particularidades do cultivo da soja em MT é que a produção, que se dá sobre solos quimicamente pobres, lixiviados por causa das chuvas abundantes no verão, e ácidos porque a longa estiagem durante o inverno aumenta a concentração de ferro e alumínio (ARACRI, 2012).

Temos, nesse caso, uma perfeita demonstração da importância das redes de cooperação para o desenvolvimento e adaptação das técnicas de produção aos contextos locais ou regionais de produção. Por causa das referidas características físico-químicas de seus solos, o emprego de fertilizantes para a produção de soja em larga escala em Mato Grosso se dá em patamares superiores ao do restante do país. De acordo com a Companhia Nacional de Abastecimento (CONAB), Mato Grosso tem o maior custo variável na produção de soja do Brasil, estando sempre acima da média nacional há várias safras. Em 2016, segundo dados da própria CONAB, os fertilizantes compreendiam 34\% dos custos operacionais totais no cultivo da soja em Mato Grosso. A média nacional nesse ano foi da ordem de $26 \%$.

Um outro exemplo interessante de círculos de cooperação com foco na modernização da produção agrícola, e que também já foi objeto de nosso interesse em outro momento (ARACRI, 2018), envolve usinas de cana-de-açúcar e universidades na região do Triângulo Mineiro. Cinco usinas da região integram o chamado "Programa de Melhoramento Genético da Cana-de-Açúcar", coordenado pela Universidade Federal de Viçosa (UFV): três usinas do Grupo Coruripe, a Usina Caetê e a Usina Santo Angelo. A UFV, que está sediada na Zona da Mata Mineira, por sua vez, faz parte da Rede Interuniversitária para o Desenvolvimento do 
Setor Sucronenergético (RIDESA), que é uma rede de pesquisa da qual fazem parte dez universidades de diversas partes do país, a maior parte delas federais.

A parceria entre as usinas e a UFV, no âmbito do "Programa de Melhoramento Genético da Cana", visa desenvolver novas cultivares de cana: (a) mais bem adaptadas às condições edafoclimáticas da região, mas que, ao mesmo tempo, também possuam elevado potencial de adaptação às características de outras regiões; (b) mais resistentes ao corte mecanizado, já que a taxa de mecanização da produção canavieira na região já supera $80 \%$, sendo que o crescimento dessa taxa foi de $35,5 \%$ entre as safras 2006/2007 e 2009/2010 e de $54,4 \%$ entre as safras 2009/2010 e 2011/2012 (dados do Centro de Tecnologia Canavieira CTC); (c) com maior teor de sacarose, que é um critério de precificação do acúcar refinado.

Os exemplos comentados acima convergem com as conclusões de Storper (1996), segundo as quais grande parte da mudança tecnológica se dá dentro de um contexto territorial. Ou, como bem assinalou Sánchez (1991), se é bem verdade que as novas tecnologias exercem influências diversas sobre o território, este, por sua vez, também influencia o desenvolvimento e a difusão das inovações técnicas, "impondo por si mesmo condicionantes segundo as características do meio físico e como espaço social historicamente produzido" (p. 265). Por outro lado, se os círculos de cooperação no campo do desenvolvimento das inovações agrícolas objetivam adequar as técnicas de produção a um conjunto de circunstâncias específicas e localizadas, essas redes, no entanto, não necessariamente possuem delimitação espacial fixa (BATHELT, MALMBERG e MASKELL, 2004), pois os agentes envolvidos em um processo produtivo localizado e regionalizado podem manter vínculos com centros produtores de conhecimento e infraestruturas de ciência e tecnologia fora de seus territórios de referência.

\section{CONSIDERAÇÕES FINAIS}

Os circuitos espaciais de produção ligados às cadeias de agronegócios no Brasil são exemplos do que Milton Santos denominou, em outro momento, de circuitos superiores da economia. Por essa razão, são produtos diretos da modernização tecnológica. No caso brasileiro, conforme visto ao longo deste trabalho, a política de pesquisa e assistência técnica rurais, associada à política de crédito rural, estabeleceu as fundações do processo de modernização do campo, representado pela progressiva incorporação de objetos industriais em algumas parcelas do espaço agrário nacional. Isso deu início à primeira etapa de integração da produção agropecuária com segmentos ligados à indústria, no caso os setores de bens de produção e de insumos para a agricultura. Os incentivos governamentais aos cultivos exportáveis e ao desenvolvimento de um setor de pesquisa agropecuária que os favorecesse atuaram como iniciativas adicionais extremamente relevantes nesse processo. Como vimos, o desdobramento dessa combinação de fatores foi o incremento da escala de produção desses produtos (a soja talvez seja um dos casos mais emblemáticos), com a produção de excedentes que possibilitaram a etapa seguinte de integração da produção primária com a indústria nesse caso, a integração com a agroindústria processadora.

Com o passar dos anos, atividades e serviços de suporte, além de empresas de capital estrangeiro, foram se agregando, tornando os circuitos mais segmentados e complexos, produzindo interações espaciais a distâncias cada vez maiores e, também, cada vez mais hierarquizadas. Mas os circuitos, à medida em que se estruturavam, contribuíram, eles mesmos, de igual maneira para a modernização do setor agrícola, deixando de ser um mero produto desta. Uma das formas através das quais isso ocorreu foi mediante a criação e/ou modernização de capitais fixos diversos: armazéns, unidades agroindustriais, instalações logísticas, infraestruturas de transportes e telecomunicações, entre outros. Além disso, a 
presença de firmas estrangeiras implica em importação de novas tecnologias desenvolvidas no exterior, sendo que muitas das quais precisam ser adaptadas aos contextos locais de produção mediante parceria com instituições científico-tecnológicas nacionais.

Esse ponto, em particular, chama a atenção para um tipo específico de círculo de cooperação frequentemente associado aos circuitos espaciais de setores ligados ao agronegócio: os relacionamentos e parcerias entre empresas e instituições ligadas ao setor produtivo e universidades e centros de pesquisa para o melhoramento de produtos e processos/técnicas de produção. Conforme visto ao longo deste trabalho, não tardou para que o governo brasileiro percebesse que a tecnologia que começava a ser introduzida no setor agrícola nacional não era diretamente transferível; isso foi verificado ainda na década de 1960, na produção agropecuária, mas esse problema logo pode ser notado, também, em outros setores de atividades. E, tendo em vista que as firmas estrangeiras tendem a não realizar pesquisa e desenvolvimento fora dos seus territórios nacionais de origem, normalmente procuram pressionar a infraestrutura de ciência e tecnologia das nações dependentes, com o intuito de influenciar sua agenda de investigação (BAUMGARTEN, 2011).

Com o presente trabalho, esperamos ter obtido êxito em nosso intuito de estimular os geógrafos que têm interesse em compreender as metamorfoses do espaço agrário brasileiro, a estudar a modernização do setor agrícola nacional, sob uma perspectiva genuinamente geográfica, porém através de uma análise integrada, na qual o exame de um dado circuito espacial de produção não prescinda de igual atenção aos seus correspondentes círculos de cooperação. No tocante à questão da modernização, significa observar, de um lado, como a constituição dos circuitos altera a composição técnica do território, não apenas incorporando a este novos objetos e reconstruindo sua base material, mas também introduzindo nele novas relações de produção, ou um novo saber-fazer; de outro, com o estudo das formas de cooperação entre setor produtivo e instituições científico-tecnológicas, devendo-se sublinhar como o território, onde a produção concretamente ocorre, condiciona os termos desses relacionamentos e os tipos de inovações que deles surgem.

\section{AGRADECIMENTOS}

Agradeço, em primeiro lugar, à professora Júlia Adão Bernardes, pelo convite que me foi feito para ministrar, em junho de 2021, a palestra que originou o presente artigo em seu curso sobre a "Geografia do Agronegócio" no Programa de Pós-Graduação em Geografia (PPGG) da Universidade Federal do Rio de Janeiro (UFRJ). Aproveito a oportunidade para agradecer, também, à Fundação de Amparo à Pesquisa do Estado de Minas Gerais (FAPEMIG) e ao Conselho Nacional de Pesquisa Científica e Tenológica (CNPq) pelo apoio às pesquisas que realizei alguns anos atrás e que foram citadas ao longo deste trabalho.

\section{NOTAS}

1 - Sobre densidade técnica e densidade normativa, ver Santos (2002).

\section{REFERÊNCIAS}

ARACRI, Luís Angelo. Os círculos de cooperação no espaço: redes de inovação no circuito espacial da cadeia carne-grãos em Mato Grosso. In BERNARDES, Júlia A.; MONTEIRO, Daniel; PEIXINHO, Dimas; MONTEIRO, Jorge; ARACRI, Luís 
Angelo; ARRUZZO, Roberta. O Setor Carne-Grãos no Centro-Oeste: Circuitos Produtivos, Dinâmicas Territoriais e Contradições. 1a. ed. Rio de Janeiro: Lamparina, 2021, p. 93-112.

Especialização produtiva regional e inovação: relacionamentos entre instituições científico-tecnológicas e empresas do setor sucroenergético no Triângulo Mineiro. Revista Espacios, Caracas, Volume 39, Número 14, p. 14-24, 2018.

. Reestruturação Produtiva, Território e Difusão de Inovações no Campo: A Agricultura de Precisão em Mato Grosso. 1a. ed. Rio de Janeiro: Arquimedes, 2012, 176 p.

BATHELT, Harald; MALMBERG, Anders; MASKELL, Peter. Cluster and knowledge: local buzz, global pipelines and the process of knowledge creation. Progress in Human Geography, Nova Iorque, Volume 28, Número 1, p. 31-56, 2004.

BAUMGARTEN, Maíra. Tecnologia e desenvolvimento. In CATTANI, Antônio e HOLZMANN, Lorena. Dicionário de Trabalho e Tecnologia. 1a. ed. Porto Alegre: Zouk, 2011, p. 398-406.

BERNSTEIN, Henry. Dinâmicas de classe da mudança agrária. 1a. ed. São Paulo: Ed. Unesp, 2011, 171 p.

CAMPI, Mercedes. Tierra, Tecnología y Innovación:. El Desarollo Agrario Pampeano en el Largo Plazo (1860-2007). 1a. ed. Buenos Aires: Prometeo Libros, 2011, 256 p.

CARLOS, Ana F. Espaço e Indústria. 1a. ed. São Paulo: Contexto, 1988, 66 p.

CASTILLO, Ricardo e FREDERICO, Samuel. Espaço geográfico, produção e movimento: uma reflexão sobre o conceito de circuito espacial. Sociedade e Natureza, Uberlândia, Volume 1, Número 3, p. 461-473, 2011.

CLAVAL, Paul. Espaço e território: as bifurcações da ciência regional. Espaço e Economia: Revista Brasileira de Geografia Econômica, Rio de Janeiro, Ano I, Número 1, p. 1-23, 2012.

. Geografia econômica e economia. GeoTextos, Salvador, Vol. 1, Número 1, p. 11-27, 2005.

DALLABRIDA, Valdir. Governança Territorial e Desenvolvimento: Descentralização Político-Administrativa, Estruturas Subnacionais de Gestão do Desenvolvimento e Capacidades Estatais. 1a. ed. Rio de Janeiro: Garamond, 2012, 544 p.

FRANCO, Marcelo e FONSECA, Giovanni. APL de biocombustíveis. In SECRETARIA DE ESTADO DE CIÊNCIA, TECNOLOGIA E ENSINO SUPERIOR. Minas Avança na Economia do Conhecimento. 1a. ed. Belo Horizonte: SECTES, 2010, p. $70-74$

GONÇALVES NETO, Wenceslau. Estado e Agricultura no Brasil: Política Agrícola e Modernização Econômica Brasileira 1960-1980. 1a. ed. São Paulo: Hucitec, 1997, 245 p.

SÁNCHEZ, Joan-Eugeni. Espacio, Economia y Sociedad. 1a. ed. Madri: Siglo XXI, 1991, 337 p.

SANTOS, Milton. O Espaço Dividido: Os Dois Circuitos da Economia Urbana dos Países Subdesenvolvidos. 2a. ed. São Paulo: Ed. USP, 2004, 440 p.

A Natureza do Espaço: Técnica e Tempo, Razão e Emoção. São Paulo: Ed. USP, 2002, 392 p.

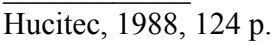

Metamorfoses do Espaço Habitado: Fundamentos Teóricos e Metodológicos da Geografia. 1a. ed. São Paulo:

SANTOS, Milton e SILVEIRA, Maria L. O Brasil: Território e Sociedade no Início do Século XXI. 1a. ed. Rio de Janeiro: Record, 2001, $471 \mathrm{p}$.

SILVA, José Graziano da. A Nova Dinâmica da Agricultura Brasileira. 1a. ed. Campinas: Ed. Unicamp, 1998, 228 p.

STORPER, Michael. Territorialização numa economia global: possibilidades de desenvolvimento tecnológico, comercial e regional em economias subdesenvolvidas. In LAVINAS, Lena; CARLEIAL, Liana; e NABUCO, Maria. Integração Regional e Regionalismo. 1a. ed. Rio de Janeiro: Bertrand Brasil, 1994, p. 13-26.

VALE, Glaucia e CASTRO, José. Clusters, arranjos produtivos locais e distritos industriais: reflexões sobre aglomerações produtivas. Análise Econômica, Porto Alegre, Volume 28, Número 53, p. 81-97, 2005. 


\section{COMO CITAR ESTE TRABALHO}

ARACRI, Luis Angelo dos Santos. Circuitos espaciais da produção, círculos de cooperação e a modernização do setor agrícola brasileiro. Revista Tamoios, São Gonçalo, v. 18, n. 1, p. 47-59, 2022. Disponível em: https://doi.org/10.12957/tamoios.2022.63437. Acesso em: DD MMM. AAAA. 